\title{
Fine structure of cell types in an ameloblastoma
}

\author{
S. K. KIM ${ }^{1}$, C. E. NASJleti ${ }^{2}$ AND L. WeAtherbEe ${ }^{3}$ \\ VA Medical Center, Ann Arbor, Michigan and Departments of Anatomy ${ }^{1}$, Oral Biology ${ }^{2}$ and Pathology ${ }^{3}$, The \\ University of Michigan, U.S.A.
}

\begin{abstract}
An unusually large and old ameloblastoma, which revealed a diverse histological appearance, was studied by light and electron microscopy. In the tumor, the epithelial component formed several patterns in the collagenous stroma. The epithelial islands, consisting of tall columnar cells surrounding the inner core of stellate cells, mimicked the cells of the inner enamel epithelium and stellate reticulum, respectively, of the normal enamel organ. The ultrastructural appearances of the columnar cells, however, were only similar to those which are seen in undifferentiated preameloblasts. Areas of squamous metaplasia were present, and these squamous cells were structurally similar to the cells at the base of the oral epithelium. Some epithelial cells containing numerous lipid granules and mitochondria formed a network of cords. The connective tissue stroma was made up of fibroblast-like cells which appear to be metabolically active. In addition, multinucleated giant cells were present in the connective tissue stroma near the epithelial component.
\end{abstract}

Accepted for publication 29 March 1979

The ameloblastoma is an epithelial odontogenic neoplasm which resembles the enamel organ of the tooth bud in its histological appearances (Gorlin et al. 1961, Evans 1968, Colby et al. 1971, Shafer et al. 1974). The tumor is not usually associated with calcified tissues and reveals diverse microscopic appearances which are seen together sometimes within the same tumor (Evans 1968). Basically, the ameloblastoma consists of epithelial elements and connective tissue stroma (Gorlin et al. 1961, Evans 1968). The epithelial elements in simple or follicular ameloblastoma form islands which resemble the enamel organ of the tooth bud. The epithelial islands consist of tall, ameloblast-like cells which surround a loose central core. The central core is made up of cells which resemble the stellate reticulum of the normal enamel organ. In other types of ameloblastoma, the epithelial elements form irregular masses or cords and sometimes reveal areas of squamous metaplasia, especially in old and large tumors.

Several previous studies have reported the ultrastructure of the ameloblastoma (Moe et al. 1961, Sujaku et al. 1968, Lee et al. 1971, Csiba et al. 1970, Navarret \& Smith 1971, Mincer \& McGinnis 1972, Tandler \& Rossi 1977). Some of these studies (Moe et al. 1961, Sujaku et al. 1968, Lee et al. 1971, Mincer \& McGinnis 1972) have dealt with the structure of tall columnar epithelial cells in the tumor and 
are in agreement that there are some structural similarities between the tumor epithelium and the normal enamel epithelium.

However, the fine structure of the columnar cells has not been described in detail, and it is unclear how closely these cells resemble the ameloblasts or the precursors of these cells. Furthermore the fine structural appearances of the cells in the connective tissue stroma have not been reported. The present study describes the ultrastructural appearances of various cells which are found in the epithelial and connective tissue components of an unusually large ameloblastoma. The tumor was made up of diverse cell types, which permit studies of many different kinds of cells. The study reveals that the ameloblastoma contains the full complement of cells normally found during odontogenesis. However, these cells resemble the dental organ at a very undifferentiated stage in the fine structural appearances.

\section{Case Report}

Specimens for this study were obtained from an ameloblastoma which was resected from the right mandible of a 51year-old white male. The patient had had the lesion in the right face for over 20 years and, during this time period, the lesion had been locally excised twice. However, he had previously rejected surgery because of religious reasons, and the tumor had been growing steadily for the 8 years prior to surgery. The patient had not been irradiated or treated with chemotherapeutic agents prior to surgery. The excised tumor mass was large and measured $16 \times 14 \times 12 \mathrm{~cm}$. The remainder of physical examination at the time of surgery was within normal limits and his postoperative recovery was unremarkable.

\section{Material and Methods}

The tissues obtained from several different regions of the tumor were sliced into smaller pieces and prepared for light and electron microscopy. The time lapse between the removal of the tumor and fixation was $10-15$ min. For light microscopy, the tumor tissues were fixed in Bouin's solution, paraffin embedded, sectioned and stained with hematoxylin and eosin. For electron microscopy, tissues were fixed for $2-3 \mathrm{~h}$ in the aldehyde fixative similar to that described by Karnovsky (1965) with the concentration of paraformaldehyde and glutaraldehyde reduced to $1.5 \%$ and $2 \%$, respectively. Following fixation, the tissues were rinsed several times in $0.1 \mathrm{M}$ cacodylate buffer and stored in the same buffer overnight in the refrigerator. The aldehyde fixed tissues were post-fixed in $1 \% \mathrm{OsO}_{4}$ in $0.1 \mathrm{M}$ cacodylate buffer and en bloc stained with $0.5 \%$ uranyl acetate solution as described by Karnovsky (1967) prior to dehydration and embedding in Epon.

The sections of en bloc stained tissues were further stained briefly (about $20 \mathrm{~min}$ ) with 1\% uranyl acetate (aqueous) followed by $10 \mathrm{~min}$ with lead citrate (Reynolds 1963). Sections were cut on a Porter-Blum MT2b ultramicrotome and studied in an Hitachi HU-11c-1 electron microscope operated at $75 \mathrm{kV}$.

\section{Observations}

\section{Light Microscopy}

The tumor consisted of epithelial elements and connective tissue stroma. The epithelium of the tumor presented diverse microscopical appearances (Figs. 1-3). The epithelial elements in many areas of 


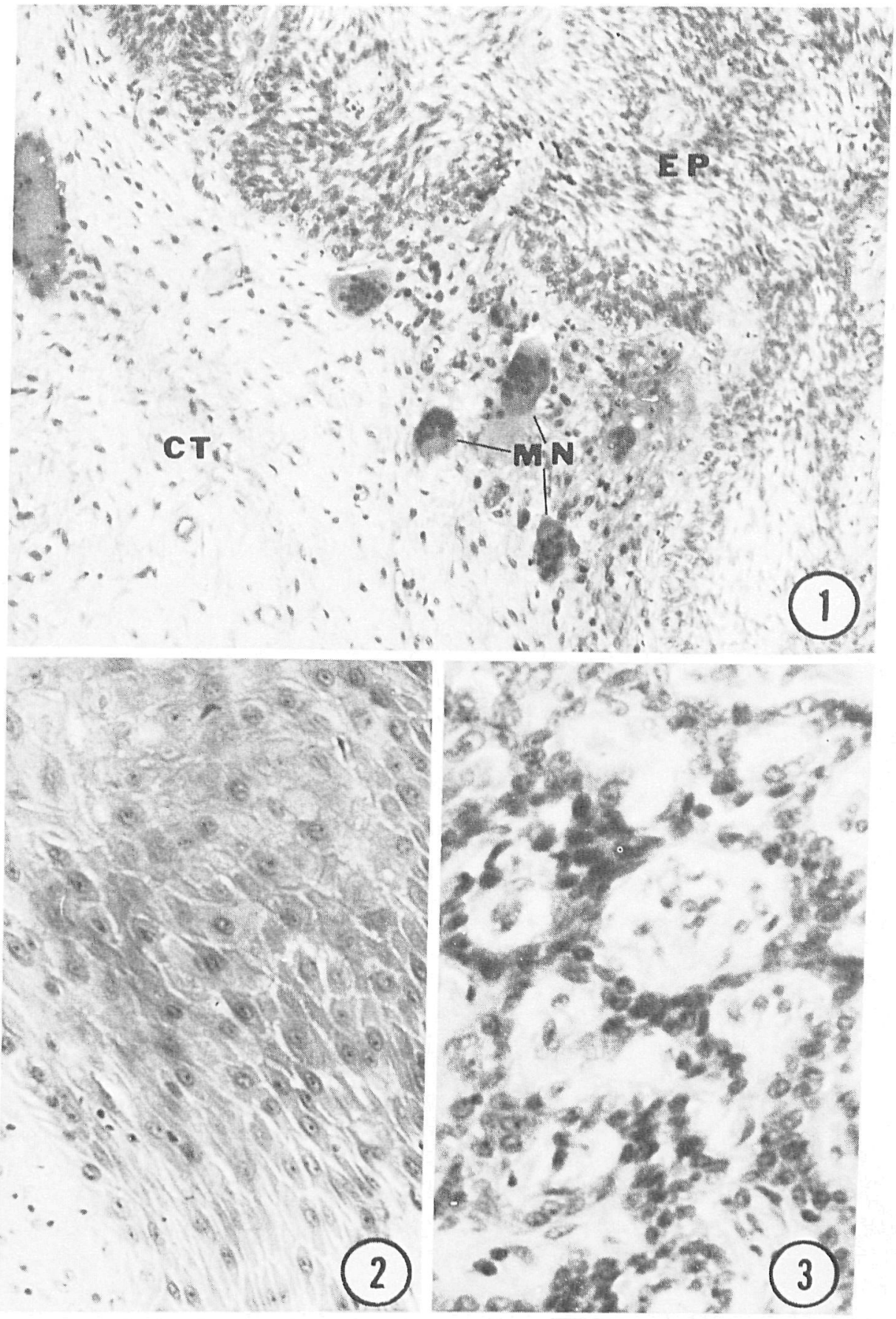

Fig. 1. A portion of the tumour in hematoxylin and eosin preparation. The epithelial component (EP) reveals columnar to spindle shaped cells surrounding the loose inner core. Several multinucleated, giant cells (MN) are located in the connective tissue stroma (CT) adjacent to the epithelium. $\times 150$.

Fig. 2. A portion of the tumor epithelium showing metaplastic squamous cells. (Hematoxylin and eosin) $\times 400$. Fig. 3. A portion of the tumor epithelium showing cells in the form of a network of cords. $(\mathrm{H} \& \mathrm{E}) \times 200$. 
the tumor formed islands which were made up of densely packed peripheral cells surrounding a loose inner core (Fig. 1). Upon close examination, a basement membrane could be seen separating the epithelial elements from the connective tissue stroma. The peripheral cells of the epithelial islands were columnar and surrounded the stellate cells located in the interior (Fig. 1.). In some areas, the tumor epithelium consisted of squamous cells (Fig.2). In other areas, the epithelial cells formed a network of cords which traversed irregularly in the connective tissue stroma (Fig. 3). The cells of these cords were somewhat cuboidal and did not appear to be associated with stellate cells.

The connective tissue stroma of the tumor (Fig. 1) consisted of a large number of irregularly shaped cells located in an eosinophilic matrix. Cellular elements of the connective tissue appeared to be mesenchymal cells or fibroblasts. In addition, large, irregularly shaped cells with multiple nuclei were present in the connective tissue stroma and often localized near the basement membrane (Fig. 1.) Frequently, these multi-nucleated giant cells were found in the areas of hemorrhage and in close proximity to the capillaries. The cytoplasm of these cells had a foamy appearance (Fig. 10a).

\section{Electron Microscopy}

\section{A. The Epithelial Components:}

The epithelial component of the tumor was delineated from the connective tissue stroma by the basal lamina which followed the contour of the epithelial cell surfaces. Upon examination at a higher magnification, hemidesmosomes were noted in places along the basal surface of the epithelial cells (micrograph not included), and no unusual feature was detected in association with the basal lamina complex. Various types of epithelial cells could be recognized by the differences in their location and /or shapes.

1. The columnar cells: Some columnar cells were more elongated than others, but these were generally tall cells with similarly elongated nuclei (Fig. 4). The nuclei revealed an irregular outline and contained prominent nucleoli. Mitochondria appeared to be somewhat swollen and were found on both sides of the nucleus near the poles. Bundles of tonofilaments and clusters of ribosomes were scattered throughout the cell and provided a dense background for the cytoplasm. Only a few arrays of rough endoplasmic reticulum were detected in the cells but with no particular pattern of orientation.

The Golgi complex stood out in the epithelial cells due to the large number of electron lucent vacuoles associated with this organelle (Fig. 4 inset). These vacuoles were spherical and of various sizes. In addition to these vacuoles, a large number of small vesicles were present around the Golgi complex. However, the Golgi complex of these cells revealed only a small number of flattened cisternae (generally two or three).

2. Stellate cells: The stellate cells revealed numerous cytoplasmic processes which were joined with those of the adjacent cells by desmosomes. The cells contained proportionately large nuclei which were centrally located, irregularly contoured and contained patches of chromatin and nucleoli (Fig. 5). In the cytoplasm, mitochondria, fragments of rough surfaced endoplasmic reticulum, some polyribosomes and bundles of tonofilaments were scattered throughout the cell. The stellate cells revealed a large number of electron dense granules of different sizes and shapes (Fig. 6). These 


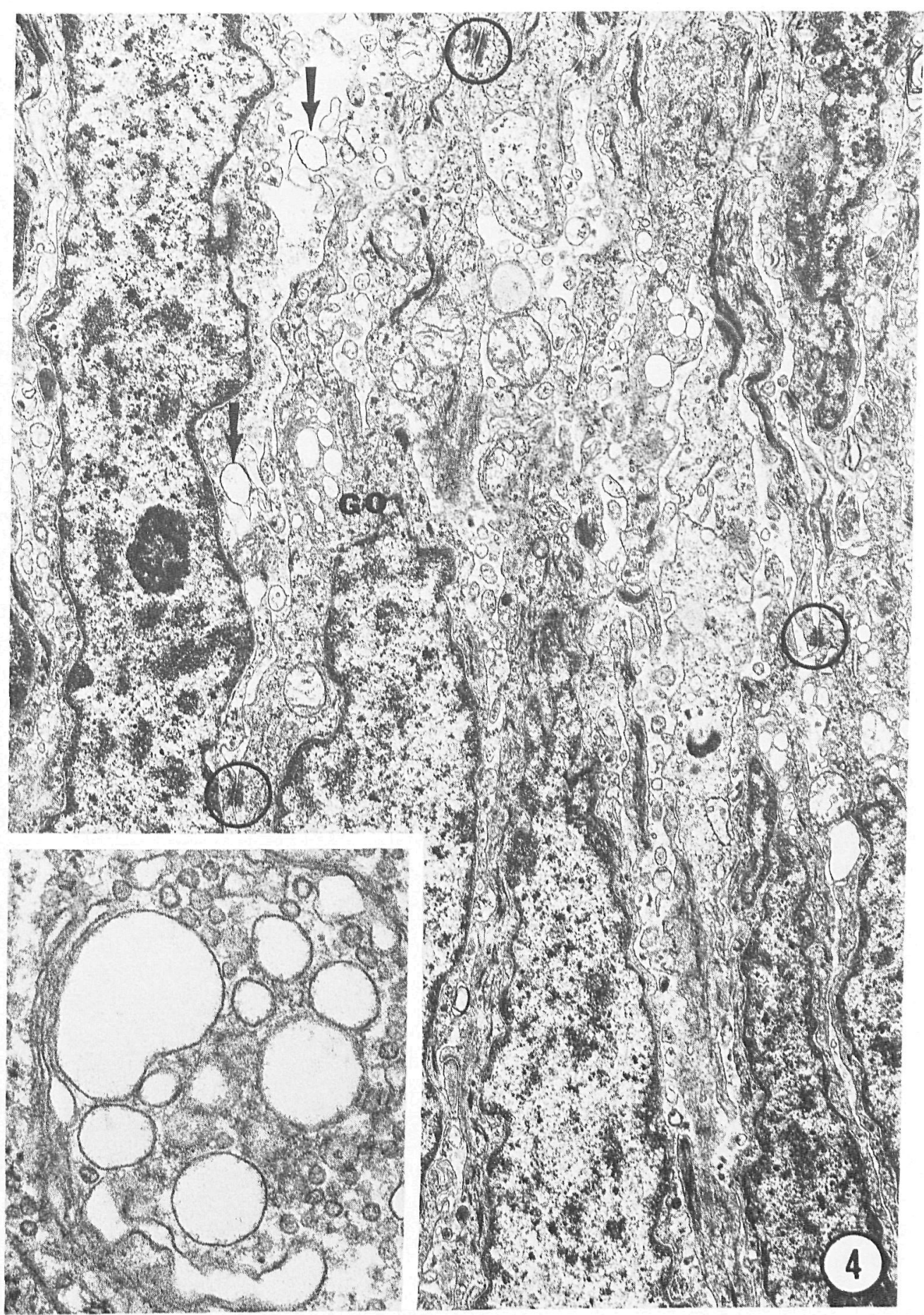

(Figs. 4.-10. Electron Micrographs except for Fig. 10a.)

Fig. 4. The columnar cells in the tumor epithelium. Nuclei are also elongated and of an irregular contour. Golgi complexes $(\mathrm{GO})$ are prominent due to large numbers of electron lucent vacuoles. Some vacuoles are also present in the intercellular space (Arrow). Other cytoplasmic organelles are scattered in the cytoplasm. Cells are held together by desmosomes (inside the circles). $\times 12,000$.

Inset. A higher magnification micrograph showing the Golgi complex of the columnar cells. It consists of electron lucent vacuoles, vesicles and cisternae. $\times 90,000$. 


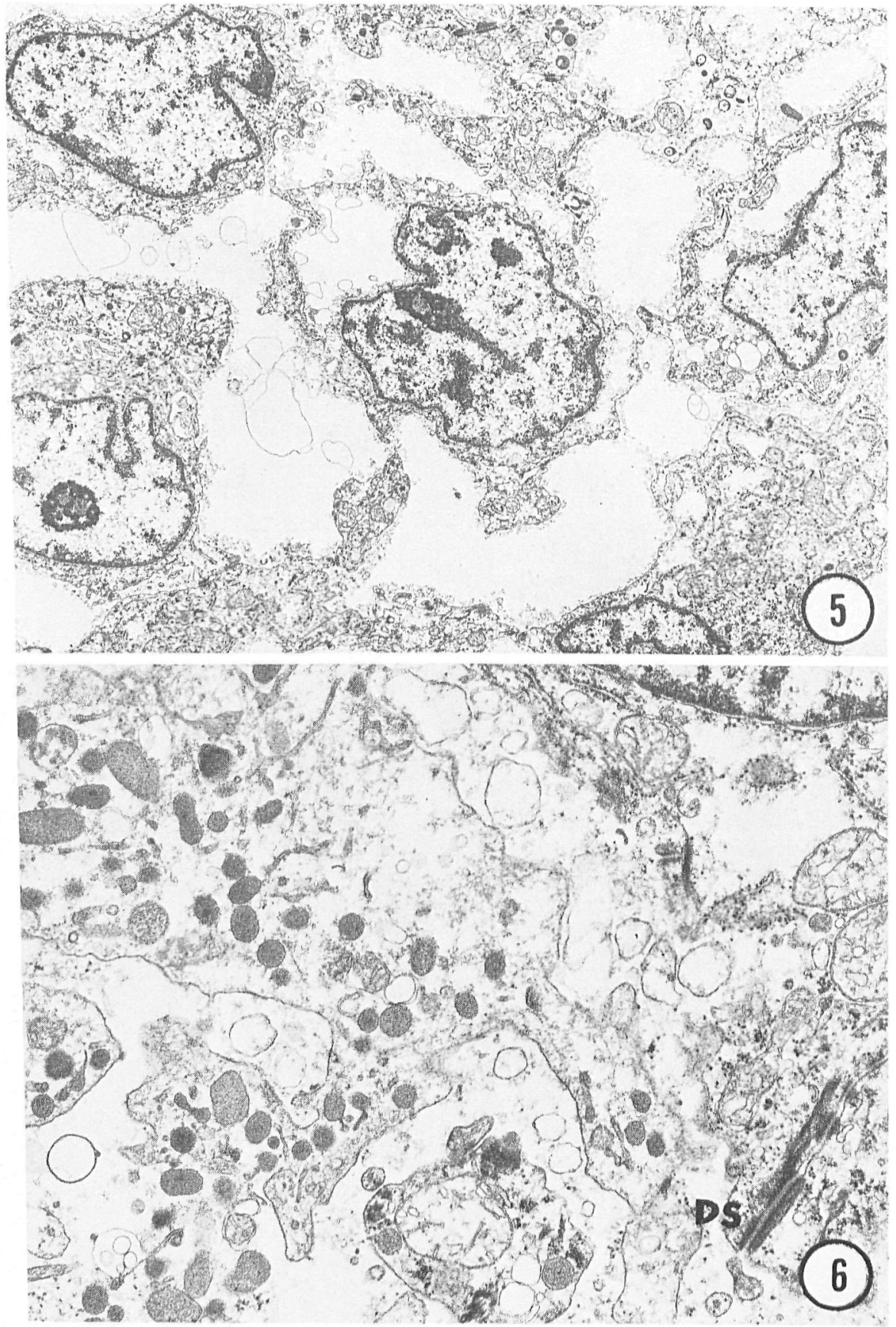

Fig. 5. Stellate cells in the loose core of the epithelial component. Nuclei are large and occupy most of the cell volume. Cells have many processes which are joined to the adjacent ones by demosomes as shown in Fig. $6 . x$ 10,000 .

Fig. 6. The cytoplasm of stellate cells showing a large number of dense, lysosome-like granules present in these cells. Cells are held together by desmosomes (DS). $\times 33,000$. 
granules appeared to be lysosomal structures. In the tumor tissue incubated for the demonstration of acid phosphatase activity, the reaction product occurred in some of these dense granules (unpublished observations).

3. Squamous cells: The squamous cells revealed large nuclei which occupied more or less the center of densely packed cytoplasm (Fig. 7a). The cytoplasmic density appeared to be due to the presence of numerous bundles of tonofilaments and membrane-bound structures, some of which were studded with ribosomes (Fig. 7b). In addition, there were larger amounts of ribosomes, dense granules, and vacuoles, as well as some microtubules.

4. Cuboidal cells: The cuboidal cells which formed cords were characterized by containing a large number of mitochondria and some lipid granules (Fig. 8). Many of these mitochondria appeared to be swollen and damaged and revealed only the remnant of cristae. These cells also revealed some tonofilaments and numerous electron lucent vacuoles similar to those found in other types of epithelial cells in the tumor. Some electron dense granules were present in these cells and appeared to be lysosomal structures.

\section{B. The Connective Tissue Stroma:}

The connective tissue stroma consisted of mostly stellate cells and fibers (Fig. 9a), except in the areas of hemorrhage where red blood cells and multinucleated giant cells were also found (Fig. 10a).

1. Cells of the connective tissue: The cells of the connective tissue generally revealed cytoplasmic processes (Fig. 9a). The cytoplasm of the cells was filled with arrays of rough-surfaced endoplasmic reticulum (Fig. 9a), the cisternae of which often revealed amorphous materials (Fig. 9b). In the Golgi regions, vesicles, irregularly shaped cisternae and some patches of amorphous dense material were clustered. Segments of the cisternae of the endoplasmic reticulum near the Golgi complexes were devoid of ribosome particles and appeared to be the transitional elements.

2. Multinucleated giant cells: The plasma membrane of the giant cells was modified into numerous microvillus-like projections (Fig. 10b). These projections and the peripheral cytoplasm exhibited an organelle-free zone which contained an amorphous, electron-dense material (Fig. 10b). More centrally, the cytoplasm contained numerous patches of polyribosomes and spherical vacuoles of varying sizes (Fig. 10b). Some of these vacuoles were filled with an electron dense material, while others seemed more electron lucent. In the central area of the cytoplasm where nuclei were clustered, fragments of rough-surfaced endoplasmic reticulum, polysomes, and Golgi complexes (vacuoles, vesicles and cisternae) were present. In addition, there were some mitochondria which appeared to be swollen, and the foamy appearance of the cytoplasm in the light microscope (Fig. 10a) appeared to be due to the presence of these mitochondria.

\section{Discussion}

The ameloblastoma observed in this study consisted of epithelial component and connective tissue stroma as described by many previous studies of this tumor. The epithelial component revealed diverse microscopical appearances and formed different patterns in different regions of the tumor. In this respect the ameloblastoma appeared to be a conglomerate of several 


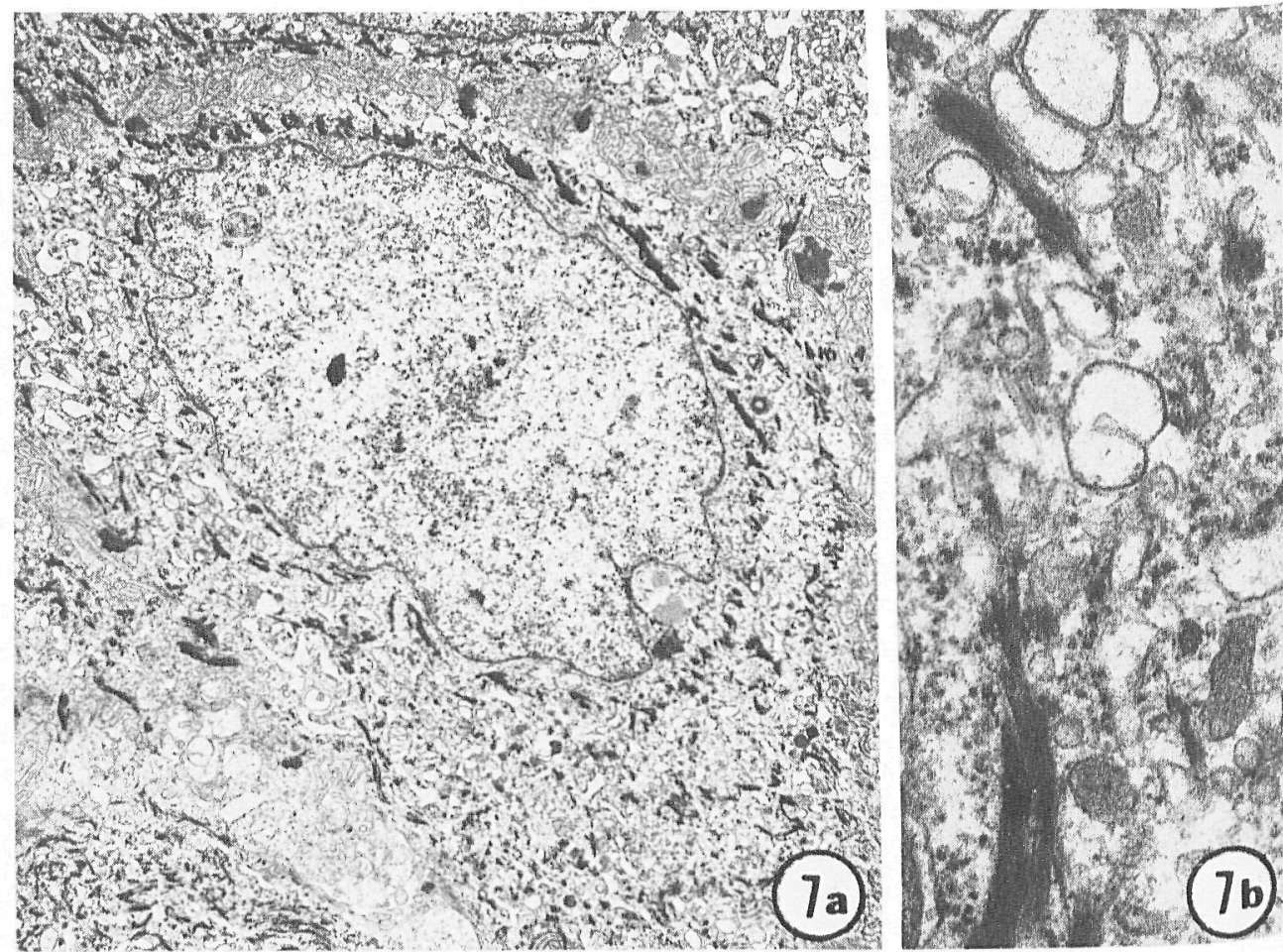

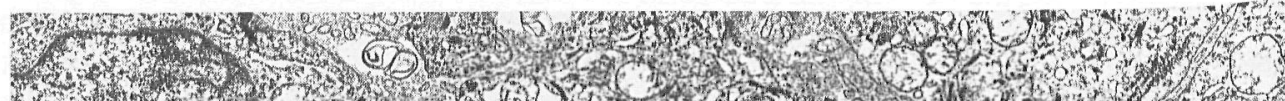

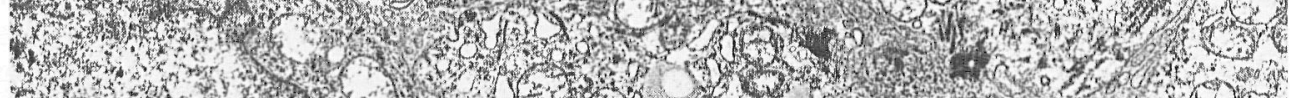
1.7.

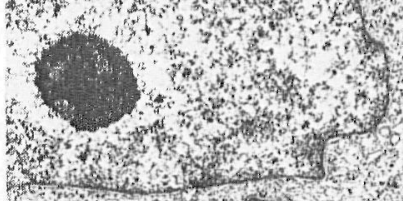

7. Why

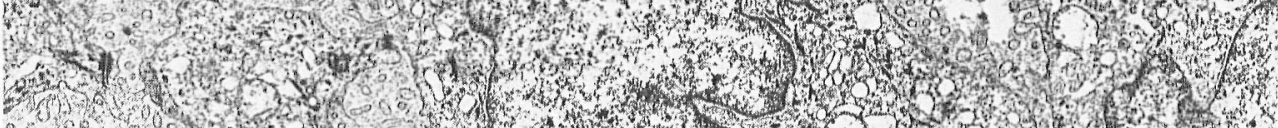

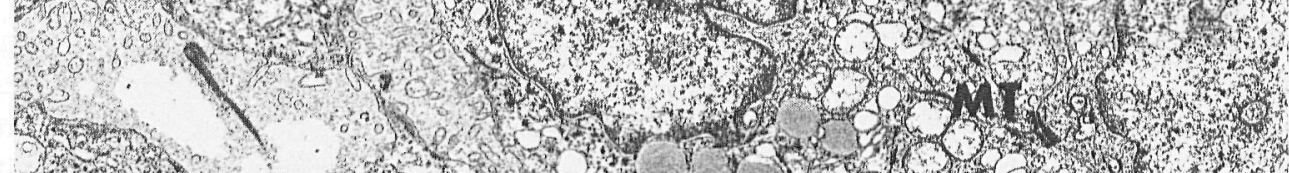

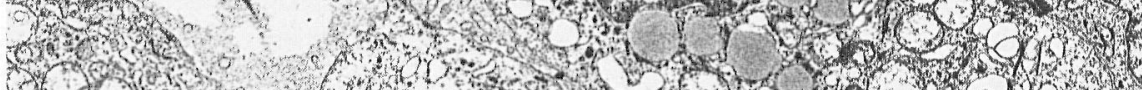

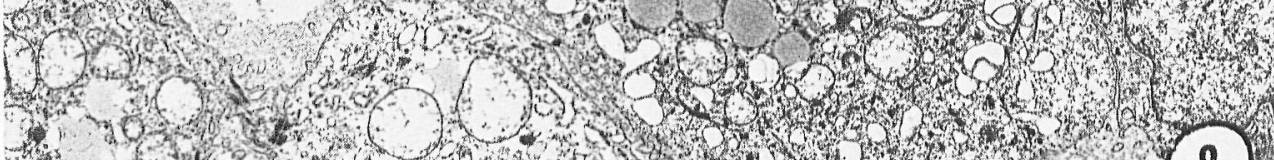

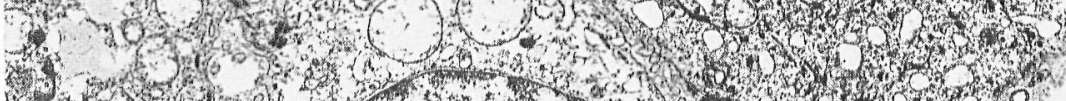

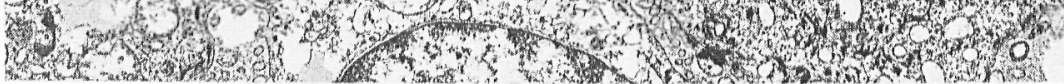


different subtypes of tumor, as pointed out previously (Gorlin et al. 1961, Evans 1968). The epithelial islands consisting of peripheral columnar cells and inner stellate cells appeared to form patterns which characterize the simple or follicular ameloblastoma. On the other hand, the epithelial islands with metaplastic squamous cells resembled the acanthomatous ameloblastoma, while the epithelial component which formed a network of cords with no stellate cells appeared to be comparable to plexiform type ameloblastoma.

It is unknown whether or not the different types of epithelial cells present in the tumor were related in any way. It is possible that the epithelium consisting of columnar and stellate cells undergoes a metaplastic transformation leading to a squamous epithelium. On the other hand, the presence of different types of epithelial cells might reflect the differences in the origin of these epithelial tumor cells. The origin of tumor cells has been suggested to be in the lining of dentigerous cysts, remnants of the dental lamina and of the enamel organ and the basal layer of the Oral mucosa (Evans 1968, Shafer et al. 1974).

Many of the previous electron microscopic studies of the ameloblastoma were based on the observations of simple or follicular types of ameloblastoma (Moe et al. 1961, Sujaku et al. 1968, Lee et al. 1971, Mincer \& McGinnis 1972). These studies have reported that the fine structural appearances of the tumor epithelium resembled those of the inner enamel epithelium. It has been suggested that the different types of cells in the tumor epithelium represented the dental lamina cells at various stages of differentiation (Moe et al. 1961). Others (Lee et al. 1971, Mincer \& McGinnis 1972) have implied that the epithelial cells of the tumor were at a fairly high level of differentiation.

The columnar cells and stellate cells in the epithelial islands of the tumor mimicked the inner enamel epithelium and stellate reticulum, respectively, of the normal enamel organ in the arrangement and appearances of these cells. However, the ultrastructural features of the columnar cells, at best, resembled the ameloblasts at a fairly undifferentiated stage.

As demonstrated by many previous studies (Garant \& Nalbandian 1968, Kallenbach 1968, 1971, Warshawsky 1968, Reith 1968, Moe 1971, Weinstock \& Leblond 1971), the secretory ameloblasts were tall columnar cells in which the organelles were fairly well segregated. Mitochondria were generally clustered in the basal cytoplasm proximal to the nucleus. The Golgi complex was localized distal to the nucleus and extended a fair distance, running longitudinally along the cell axis. An abundant amount of rough endoplasmic reticulum was localized at the periphery of the Golgi complex. The distal

Fig. 7 a. Cells of the metaplastic squamous epithelium. Bundles of tonofilaments form a shell around the centrally located nucleus in a cell. $\times 10,000$.

Fig. 7b. A high magnification view to the cytoplasm of a squamous cell. The cytoplasm is packed with bundles of tonofilaments and clusters of ribosomes. In addition, there is a large number of light and dense vesicular structures. $\times 90,000$.

Fig. 8. The cuboidal cells of the epithelial cords. The cells reveal numerous mitochondria (MT) which appear to be $s w_{0} l l e n$ and damaged. Dense, lipid granules are clustered in the cytoplasm adjacent to the nucleus. Bundles of tonofilaments as well as lysosome-like granules can also be seen upon close examination of the cell. $\times 8,000$. 


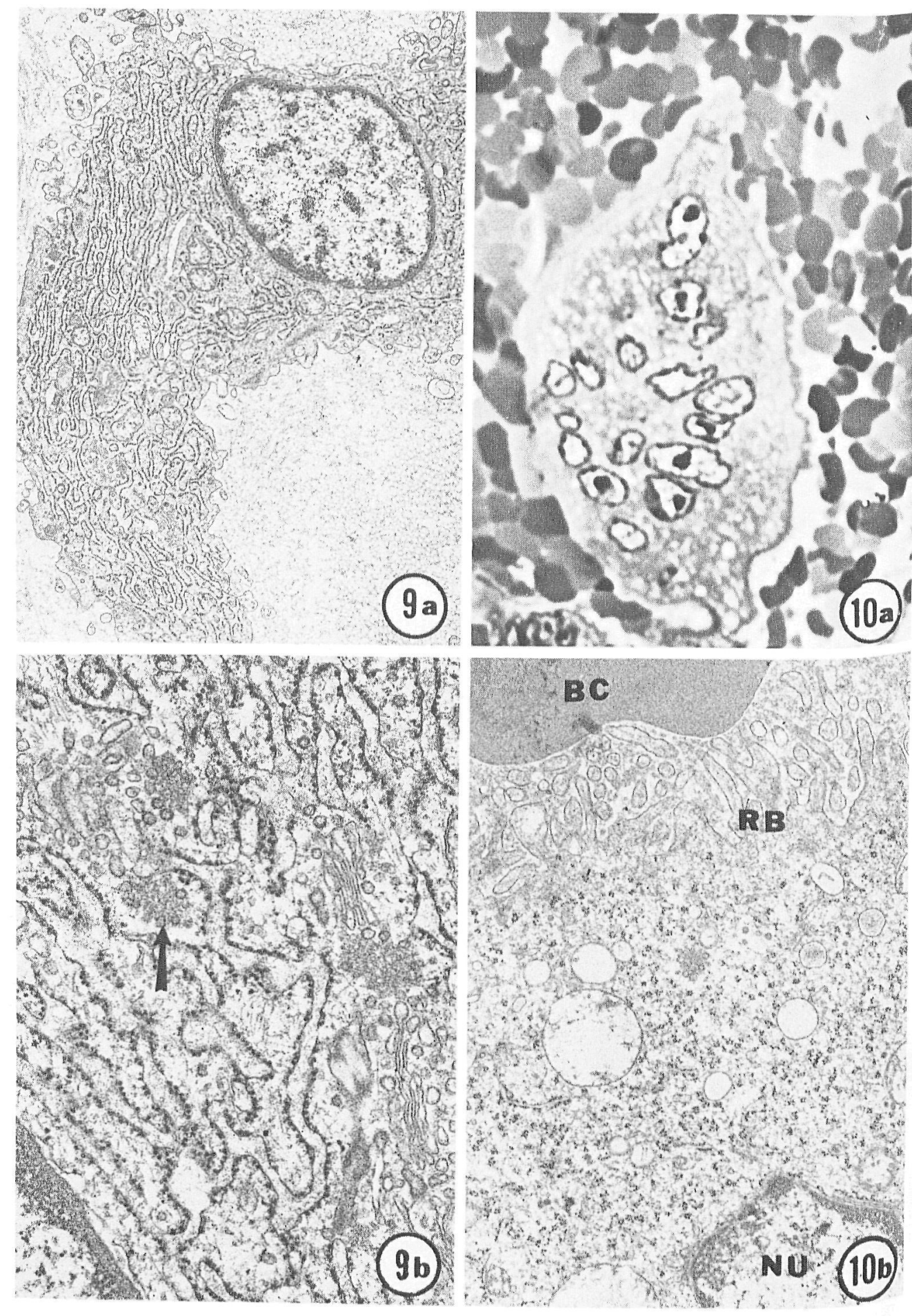


cytoplasm above the terminal web was characterized by the presence of Tome's process.

In the columnar cells of the tumor, however, the cytoplasmic organelles were scattered throughout the cytoplasm and showed no signs of being segregated. Furthermore, these cells revealed many free ribosomes instead of rough endoplasmic reticulum. In this respect, the columnar cells of the tumor resembled the cells of the inner enamel epithelium at an early stage of differentiation.

Despite the undifferentiated appearance of the columnar cells, the Golgi complexes of these cells revealed a large number of vacuoles as the Golgi complexes of the secretory ameloblasts (Garant \& Nalbandian 1968, Reith 1968, Kallenbach 1971, Moe 1971, Weinstock \& Leblond 1971, Katchburian \& Holt 1972) and other cells with an active secretory function. Unlike the condensing vacuoles in other secretory cells, however, the vacoules associated with the Golgi complexes of the columnar cells were electron lucent. Since these cells did not seem to contain any secretory granules, it is unclear what the content of these vacuoles was or what was the fate of the material contained in them.

The stellate cells of the tumor epithelium were in many respects similar to the stellate reticulum of the normal enamel organ. As in the stellate reticulum of the enamel organ in rats (Reith 1968), cells were joined by desmosomes and the nucleus occupied a central position within the cell. The perinuclear cytoplasm contained the usual organelles such as mitochondria, tonofilaments, endoplasmic reticulum and dense granules. The dense granules in the tumor cells appeared to be lysosomes.

Lysosome-like granules were present in the granular cell ameloblastoma (Navarret \& Smith 1971, Tandler \& Rossi 1977). Since it has been suggested that the granular cells evolved from stellate and other epithelial cells (Evans 1968), the stellate cells of the tumor might be comparable to the precursors of the granular cell ameloblastoma. On the other hand, lysosomes are known to be concerned with the localized digestion of the intracellular organelles (Novikoff \& Essner 1962, deDuve 1963, Hruban et al. 1963, Kim et al. 1973), or the complete lysis of cells (Hirsch et al. 1963, Brandes \& Bertini 1965). Then, the lysosomes in the stellate cells of the tumor epithelium might have been related to the lytic activity of the cells, leading to the formation of microcysts which are often observed in the ameloblastoma (Evans 1968).

The squamous epithelial cells and cuboidal cells of the cords bore no close resemblance to the ameloblasts or the pre-

\footnotetext{
Fig. $9 a$. A cell in the connective tissue stroma of the tumor. The cytoplasm is filled with highly developed cisternae of the endoplasmic reticulum. The matrix is filled with collagen-like fibers. $\times 7,000$

Fig. 9b. A small portion of a connective tissue cell in the stroma showing the arrays of rough surfaced endoplasmic reticulum and Golgi complexes. The Golgi Complex consists of numerous cisternae and vesicles. Some vesicles are located at the periphery of amorphous masses (one indicated by arrow). The cisternae of the endoplasmic reticulum contain some dense materials. $\times 82,000$.

Fig. 10a. A multinucleated giant cell of the cell of the tumor in $1 \mu$ section. The cytoplasm appears foamy. Note the presence of a large number of red blood cells surrounding the cell. $\times 800$.

Fig. 10b. A portion of multinucleated giant cell showing the ruffled border (RB) consisting of microvillus-like pro jections touching upon the red blood cell (BC). Toward the interior of the cell, dense and less dense vacuoles, ribosomes and endoplasmic reticulum are seen near a nucleus (NU.) Some of the vacuole-like structures might be swollen mitochondria. $\times 15,000$.
} 
cursors of these cells. The fine structural features shown by the squamous epithelial cells were similar to those which are observed in basal cells and lower prickle cells of the oral mucosa (Silverman 1971, Squier 1971), especially in the epithelium of the palatal mucosa (Silverman 1971). The tumor epithelial cells were joined to the adjacent ones by numerous desmosomes and contained large amounts of tonofilament bundles, free ribosomes and vesicular structures. The tumor cells, however, did not reveal membrane coating granules (Martinez 1971, Hayward 1973) or any characteristics of keratinizing epithelium (Martinez 1971, Hayward et al. 1973).

The cuboidal cells, on the other hand, were more difficult to characterize. These cells contained only a moderate amount of tonofilaments but contained lipid granules and many mitochondria which appeared swollen and damaged. The appearance of mitochondria and the presence of lipid granules in these cells suggested that the cells might be aged and degenerating. The increase in the number of pleomorphic mitochondria, as in oncocytes (Tandler 1966, Kim et al. 1973), as well as the increase in the amount of lipid in the form of lipofuscin granules (Reichel 1968, Bogart 1970), are the changes frequently observed in cells as a function of age.

The connective tissue stroma did not reveal any signs of calcification. The presence of a large amount of collagen-like materials and the fine structural appearances shown by the cells indicated that the connective tissue cells were active in collagen synthesis. The connective tissue cells were stellate and resembled fibroblasts. The endoplasmic reticulum was well developed and Golgi complexes were elaborate as in fibroblasts, secretory odontoblasts (Reith 1968, Weinstock \& Leblond 1974) or other cells which actively synthesize collagen.
The multinucleated giant cells in the connective tissue stroma were often found surrounded by elements of the blood. The presence of giant cells could have been due to inflammatory reactions to injury and hemorrhage as in giant cell epulis (Robbins 1967). On the other hand, the fine structural appearances of these giant cells also bore a close resemblance to those of the osteoclasts (Gonzalez \& Karnovsky 1961, Scott 1967, Cameron 1969).

The presence of these giant cells and highly active fibroblast-like cells of connective tissue, in addition to the epithelial component resembling the enamel epithelium, suggested that the ameloblastoma contained the complement of cells normally found during odontogenesis. The tumor cells revealed a varying degree of differentiation. However, when viewing the epithelial and connective tissue components as a whole, the tumor, at best, resembled the dental organ at a very early stage of development.

\section{Acknowledgments}

This work was supported by the Medical Research Service of the Veterans Administration. We thank Virginia Hartog for her technical assistance and effort in preparation of this manuscript.

\section{References}

Bogart. B. I. (1970) The effects of aging on the rat submandibular gland: An ultrastructural, cytochemical and biochemical study. Journal of Morphology 130, 337-351.

Brandes, D. \& Bertini, F (1965) Role of lysosomes in cellular lytic processes: II. Cell death during holocrine secretion in sebaceous glands. Experimental and Molecular Pathology 4, 245-265. Cameron, D. A. (1969) The fine structure and 
function of bone cells. In The Biological Basis of Medicine, Vol. 3, eds. Bittar, E. E. \& Bittar, N., pp. 407-420. New York and London: Academic Press.

Colby, R. A., Kerr, D. A. \& Robinson, H. B. G. (1971) Color Atlas of Oral Pathology, 3rd edn. Philadelphia: J, B. Lippincott Co.

Csiba, A., Okros, I., Dzsinich, C. \& Szabo, D. (1970) Virus-like particles in a human ameloblastoma. Archives of Oral Biology 15, $817-826$.

de Duve, C. (1963) General properties of lysosomes: the lysosome concept. In Lysosomes, eds. deReuck, A. V. S. \& Cameron, M.P., p. 1. Boston: Little, Brown \& Co.

Evans, R. W. (1968) Adamantinoma. In Histological Appearances of Tumors, p. 964. Baltimore: The Williams and Wilkins Co.

Garant, P. R. \& Nalbandian, J. (1968) Observations on the ultrastructure of ameloblasts with special reference to the Golgi complex and related components. Journal of Ultrastructure Research 23, $427-443$.

Gonzales, F. \& Karnovsky, M. J. (1961) Electron microscopy of osteoclasts in healing fractures of rat bone. Journal of Biophysical and Biochemical Cytology 9, 299-316.

Gorlin, R. J., Chaudhry, A. P. \& Pindborg, J. J. (1961) Odontogenic tumors. Classification, histopathology and clinical behavior in man and domestic animals. Cancer 14, 73-101.

Hayward, A. F. (1973) Electron microscopic observations on cell coat and non membranecoating granules of the epithelium of the hard and soft palate in the rat. Archives of Oral Biology 18, 67-75.

Hayward, A. F., Hamilton, A. I. \& Hackermann, M. A. (1973) Histological and ultrastructural observations on the keratinizing epithelia of the palate of the rat. Archives of Oral Biology 18 , 1041-1057.

Hirsch, J. G., Bernheimer, A. W. \& Weissmann, G. (1963) Motion picture study of the toxic action of streptolysins on leucocytes. Journal of $E x$ perimental Medicine 118, 223-228.

Hruban, Z., Spargo, B., Swift, H., Wissler, R. W. \& Kleinfeld, R. G. (1963) Focal cytoplasmic degradation. American Journal of Pathology 42 , 657-683.

Kallenbach, E. (1968) Fine structure of rat incisor ameloblasts during enamel maturation. Journal of Ultrastructure Research 22, 90-119.

Kallenbach, E. (1971) Electron microscopy of the differentiating rat incisor ameloblasts. Journal of Ultrastructure Research 35, 508-531.
Karnovsky, M. J. (1965) A formaldehydeglataraldehyde fixative of high osmolality for use in electron microscopy. Journal of Cell Biology $27,137 \mathrm{~A}-138 \mathrm{~A}$.

Karnovsky, M. J. (1967) The ultrastructural basis of capillary permeability studied with peroxidase as a tracer. Journal of Cell Biology 35, 213-236.

Katchburian, E. \& Holt, S. J. (1972) Studies on the development of ameloblasts I. Fine structure. Journal of Cell Science 11, 415-447.

Kim, S. K., Weatherbee, L. \& Nasjleti, C. E. (1973) Lysosomes in the epithelial component of Warthin's tumor. Archives of Pathology $95,56-62$.

Lee, K. W., El-Labban, N. G. \& Kramer, I. R. H. (1971) Ultrastructure of simple ameloblastoma. Journal of Dental Research 50, 1194.

Martinez, I. R. (1971) Membrane-coating granules and membrane modifications in keratinizing epithelia. American Journal of Anatomy 130 , 93-119.

Mincer, H. H. \& McGinnis, J. P. (1972) Ultrastructure of three histological variants of the ameloblastoma. Cancer 30, 1036-1045.

Moe, H. (1971) Morphological changes in the infranuclear portion of enamel producing cells during their life cycle. Journal of Anatomy 108 , $43-62$.

Moe, H., Clausen, F. \& Philipsen, H. P. (1961) The ultrastructure of simple ameloblastoma. Acta Pathologica et Microbiologica Scandinavica 2, $140-154$.

Navarret, A. R. \& Smith, M. (1971) Ultrastructure of granular cell ameloblastoma. Cancer 27 , 948-955.

Novikoff, A. B. \& Essner, E. (1962) Cytolysosomes and mitochondrial degeneration. Journal of Cell Biology 15, 140-146.

Reichel, W. (1968) Lipofuscin pigment accumulation and distribution in five rat organs as a function of age. Journal of Gerontology 23, 145-153.

Reith, E. J. (1968) Collagen formation in developing molar teeth of rats. Journal of Ultrastructure Research 21, 383-414.

Reynolds, E. S. (1963) The use of lead citrate at high $\mathrm{pH}$ as an electron opaque stain in electron microscopy. Journal of Cell Biology 17 , $208-212$.

Robbins, S. L. (1967) Pathology, Vol. 2, p. 788. Philadelphia: Saunders.

Scott, B. L. (1967) Thymidine- ${ }^{3} \mathrm{H}$ electron microscope radioautography of osteogenic cells in the fetal rat. Journal of Cell Biology 35, 115-126.

Shafer, W. G., Hine, M. K. \& Levy, B. M. (1974) A Textbook of Oral Pathology, 3rd edn. pp. 
251-258. Philarelphia: W. A. Saunders Co.

Silverman, S. (1971) Nonkeratinization and keratinization: The extremes of the human range. In Current Concepts of Oral Mucosa, eds. Squier, C. A. \& Meyer, J. Springfield, Illinois: Charles C. Thomas.

Squier, C. A. (1971) Ultrastructural features of oral epithelium. In Current Concepts of Oral Mucosa, eds. Squier, C. A. \& Meyer, J., pp. 5-33. Springfield, Illinois: Charles C. Thomas.

Sujaka, C., Oo, T., Tokoshima, A., Kopa, T., Matsuo, T. \& Kuhara, T. (1968) An electron microscopic observation of the ameloblastoma. Kurume Medical Journal 15, 127-131.

Tandler, B. (1966) Fine structure of oncocytes in human salivary gland. Virchows Archiv: Abteilung A. Pathologische Anatomie 341, 317-326.

Tandler, B. \& Rossi, E. P. (1977) Granular cell ameloblastoma: Electron microscopic observations. Journal of Oral Pathology 6, 401-412.
Warshawsky, H. (1968) Fine structure of secretory ameloblasts in rat incisors. Anatomical Record $161,211-229$.

Weinstock, A. \& Leblond, C. P. (1971) Elaboration of the matrix glycoprotein of enamel by the secretory ameloblasts of the rat incisor revealed by radioautography after galactose- ${ }^{3} \mathrm{H}$ injection. Journal of Cell Biology 51, 26-51.

Weinstock A. \& Leblond, C. P. (1974) Synthesis, migration, and release of precursor collagen by odontoblasts as visualized by radioautography after $\left({ }^{3} \mathrm{H}\right)$ proline administration. Journal of Cell Biology 60, 92-127.

Address:

Dr.S.K.Kim

Research Service

$V A$ Medical Center

2215 Fuller Road

Ann Arbor, MI 48105

U.S.A. 
This document is a scanned copy of a printed document. No warranty is given about the accuracy of the copy. Users should refer to the original published version of the material. 